\title{
Evaluación de Tres Variables de Crecimiento del Pleurotus pulmonarius sobre Tusa de Maíz Empleando Procesamiento Digital de Imágenes
}

\author{
Juan C. Oviedo(1), Ana E. Casas(1), Jaime A. Valencia ${ }^{(2)}$ y Lucas García ${ }^{(3)}$ \\ (1) Univ. Pont. Bolivariana, Esc. de Ingenierías, Cir.1 No. 70 -01. Medellín-Colombia \\ (e-mail:juan.oviedo@upb.edu.co; ana.casas@upb.edu.co) \\ (2) Univ. de Antioquia, Dpto. Ing. Eléctrica, Calle 67 №. 53-108, Medellín-Colombia \\ (e-mail: valenciajaime1@gmail.com) \\ (3) Ing. Agroindustrial, Univ. Pont. Bolivariana. Cir.1 No. 70 -01. Medellín-Colombia \\ (e-mail: lucasgarciaestrada@gmail.com)
}

Recibido Dic. 4, 2015; Aceptado Feb. 8, 2016; Versión final Abr. 5, 2016, Publicado Oct. 2016

\begin{abstract}
Resumen
Se cultivó el basidiomiceto Pleurotus pulmonarius sobre tusa de maíz en cajas de Petri para evaluar el crecimiento o su vigor, estudiando dos niveles de las variables humedad, $\mathrm{pH}$ y contenido de sales, midiendo su crecimiento a través imágenes poli cromáticas procesadas en Matlab, empleando un algoritmo para calcular su color. Uno de los inconvenientes de la fermentación en estado sólido, es la dificultad del seguimiento al crecimiento celular. Los métodos tradicionales de medición son procedimientos largos y costosos, razón por la cual se deben buscar alternativas para su medición como el procesamiento digital de imágenes que se realizó en este trabajo. El análisis estadístico se llevó a cabo en el software Statgraphics centurión XVI. El análisis presentó una diferencia estadísticamente significativa para el contenido de humedad y la presencia o ausencia de sales. Los mejores niveles de las variables fueron $80 \%$ de humedad, $\mathrm{pH}=6$ y presencia de sales.
\end{abstract}

Palabras clave: procesamiento digital de imágenes; Pleurotus pulmunarius; fermentación en estado sólido; biomasa

\section{Evaluation of Three Variables of Growth of Pleurotus pulmonarius on Corncob Using Digital Image Processing}

\begin{abstract}
Basidiomycete Pleurotus pulmonarius was cultivated on corncob in a Petri dish to evaluate its growth or vigor, analyzing the effect of humidity, $\mathrm{pH}$ and salt content in two levels, measuring its growth through polychromatic images processed using Matlab. One of the main drawbacks of solid-state fermentation is the difficult monitoring cell growth. The conventional methods of measurement are lengthy and costly procedures, reason by which alternatives must be seek for its measurement, being as possible tool that might be used is digital processing of images as done in this work. Statistical analysis was performed using Statgraphics Centurion XVI software. The analysis presented statistically significant difference for the moisture content and the presence or absence of salts. The maximum growth of Pleurotus pulmonarius was obtained with $80 \%$ moisture, $\mathrm{pH}=6$ and presence of salts.
\end{abstract}

Keywords: digital image processing; Pleurotus pulmonarius; solid state fermentation; biomass 


\section{INTRODUCCIÓN}

La fermentación en estado sólido (FES), es un proceso biológico que se desarrolla en un material no soluble, donde un microorganismo, emplea dicho material como soporte y fuente de nutrientes en ausencia de fase líquida (Hölker y Lenz, 2005; Rodríguez et al., 2005; Velmurugan et al., 2011). La FES tiene unas ventajas, como son una baja inversión de capital y de suministro de energía, empleo medios de cultivo simples que en muchos casos provienen de desechos agroindustriales, los procesos de remoción de calor son relativamente sencillos y eficientes; de otro lado, los productos obtenidos en muchos casos pueden ser almacenados sin ninguna operación unitaria como la deshidratación. (Raimbault, 1998; Padey et al., 2008; Mitchell, et al., 2006; Guevara et al., 2012). Ejemplos de procesos de FES son el cultivo de hongos comestibles, compostaje y ensilaje (Vega y Franco, 2013). En contraposición, la FES presenta unas desventajas, como son las dificultades en el escalado de bioreactores, baja eficiencia del mezclado (Mitchell et al., 2006), entre otros. Sin embargo, uno de las mayores inconvenientes que tiene la FES, es la medición de la biomasa (Shingania et al., 2009); esta última desventaja, ha retrasado la aplicación de la FES a los procesos industriales; algunas de las principales razones que pueden explicar lo anterior, son la dificultad de separar el microorganismo del sustrato además de la existencia de los gradientes de concentración de biomasa, temperatura y humedad en las muestras (Cunha et al., 2012).

Las metodologías tradicionales, para la medición de la biomasa en FES, si bien es cierto son bien conocidas en el ámbito científico, tienen algunos inconvenientes: Utilizan para su medición gran cantidad de reactivos, los cuales se deben preparar previamente, extendiendo los tiempos del proceso; en caso de que no se preparen los anteriores reactivos y se compren, dichos compuestos implican un incremento en el costo del proceso. Por otra parte, estas metodologías exigen el empleo de equipos costosos como digestores, tituladores, espectrofotómetros, citrometros, microscopios especializados, entre otros, los cuales requieren además una infraestructura robusta para su ubicación y personal capacitado para su manejo (Arnal, 2013). Adicional a lo expuesto, hay que indicar que los residuos generados de dichos análisis, deben tener una disposición correcta, para evitar daños al medio ambiente. Sintetizando lo anteriormente mencionado, los procesos son más largos y costos. De otro lado, lo heterogéneo de la muestra debido a los gradientes antes mencionados, dificultan el seguimiento del crecimiento de la biomasa.

En bioprocesos, el monitoreo del crecimiento es fundamental para muchos estudios, tanto en la industria como para las aplicaciones experimentales, ya que proporciona tanto al científico como al productor, información muy valiosa para optimizar el proceso y reducir costos (Cordoba et al., 2010; Ortega et al., 2015b). Para la FES, se han adoptado diferentes metodologías para la medición indirecta de la biomasa, dentro de las que se destacan la medición del oxígeno suministrado o el $\mathrm{CO}_{2}$ producido; la determinación de algún componente celular especifico como glucosamina, ergosterol, proteínas o ácidos nucleicos. Igualmente se pueden mencionar métodos como el cambio en peso seco en el tiempo, medición de la producción de calor durante el cultivo, la espectroscopia por infrarrojo cercano, densidad óptica y citrometría de flujo entre otros (Oviedo et al., 2014; Cunha et al, 2012; Cordoba et al., 2010).

De lo que se ha explicado hasta aquí, surge la necesidad de buscar alternativas para la medición de biomasa en FES; una metodología alterna es el procesamiento digital de imágenes (PDI). EI PDI es una técnica de procesamiento de imágenes, donde a partir de imágenes digitales se puede extraer información significativa o importante de diferentes parámetros y/o variables (Khodaskar y Ladhake, 2015). El PDI ha tomado fuerza ya que proporciona una respuesta rápida, económica y menos laboriosa que los análisis químicos. (Becker et al., 1996; Oviedo et al, 2014). Varios autores se han dedicado al estudio del PDI para medir biomasa tanto en fermentaciones líquidas como sólidas. En fermentaciones líquidas, el PDI se ha empleado para identificar y caracterizar colonias de basidiomicetos (Dörge et al., 2000). Para el caso de la FES, una de las aplicaciones en las que se ha empleado el PDI, ha sido la cuantificación de biomasa fúngica (Firrao et al., 2010; Duan et al., 2012; Cunha et al, 2012).

Teniendo en cuenta lo anterior, se considera pertinente formular algunos conceptos relacionados con el PDI. Una imagen es la representación del efecto de la luz que reflejan los diferentes objetos sobre sobre una superficie plana. Por su parte una imagen digital, es la representación bidimensional de una imagen a partir de una matriz numérica. Matemáticamente, es la transformación a valores numéricos, los cuales pueden entenderse como una matriz de " $n$ " filas por " $m$ " columnas, donde cada celda es un pixel, siendo este último el término, el más usado para denotar los elementos de una imagen digital (Gonzales y Wood, 2008; Mauro et al., 2014). En la ecuación 1, se muestra el modelo matricial de una imagen digital.

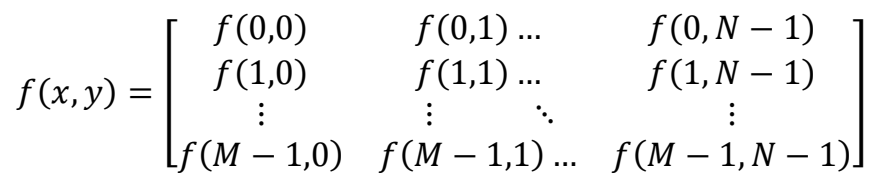


Cada pixel contiene la información de la imagen y según lo que se almacene da lugar a diferentes tipos de formatos (Gonzales y Wood, 2008). Si la imagen es en blanco y negro (figura 1 A), el valor en cada pixel tomaría solo valores de 0 si la intensidad es nula (negro) y de 1 si es blanco, que es la máxima intensidad. Si la imagen digital es en tonalidades de grises (figura $1 \mathrm{~B}$ ), cada pixel tendrá un valor entre 0 y 1 según la intensidad del gris; mientras más claro se acerca al 1 y mientras más oscuro se acerca al 0 . En las imágenes policromáticas (figura $1 \mathrm{C}$ ) cada pixel representa la información de la luz como la intensidad de 3 colores, el rojo (red), el verde (green) y el azul (blue); esta es una de las escalas para medir la intensidad del color, más conocida como escala RGB (por sus siglas en ingles Red, Green and Blue), que la incluyen la mayoría de los editores de fotos digitales en los computadores. En las imágenes policromaticas, la intensidad del color es un vector de valores entre 0 y 1 , resultado de la combinación de la intensidad de cada uno de estos colores. En los medios digitales esta información se guarda como arreglos matriciales, donde las imágenes en blanco-negro y las de tonalidades en grises solo requieren una matriz de información, mientras que las imágenes policromáticas requieren de 3 matrices de información, una por cada color primario (Mauro et al., 2014; Jacobson, 2010; Wayne, 2014)

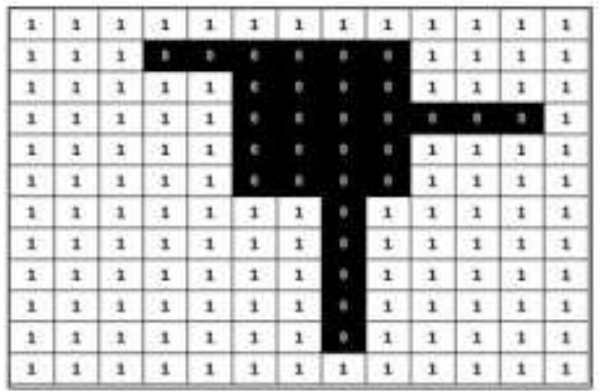

A. Imagen Digital Blanco y Negro

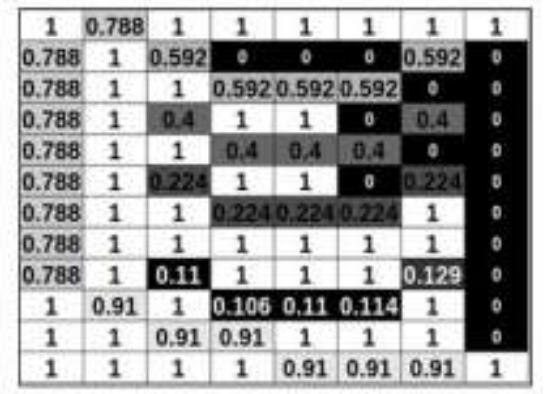

B. Imagen en Tonalidad de Grises

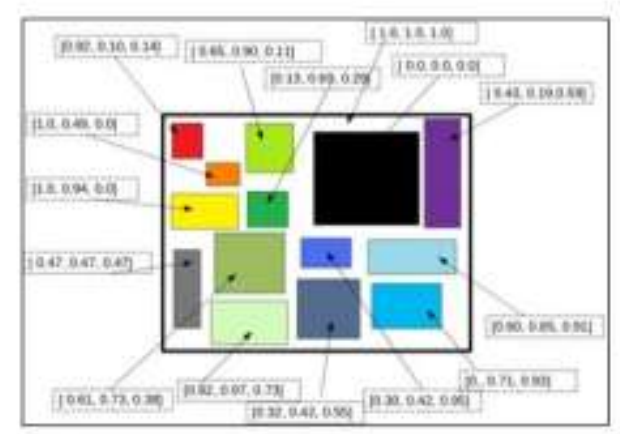

C. Imagen Digital Policromatica

Fig. 1: Tipos de imágenes digitales

Este trabajo pretende entonces aplicar el PDI como alternativa para la medición del crecimiento del Pleurotus pulmonarius sobre tusa de maíz, estudiando la influencia de tres variables que afectan su crecimiento: la humedad, el pH y la presencia (o ausencia) de sales, que son tres de los factores físicoquímicos más importantes dentro del estudio la FES (Padey et al., 2008). Para ello, se empleó como variable de respuesta los valores arrojados por una escala policromatica (RGB), que tiene como finalidad interpretar su crecimiento a través de la cuantificación del color, por medio de un algoritmo diseñado en Matlab y de esta manera proponer una metodología para medir el crecimiento de basidiomicetos en medio sólido, que reduce costos, tiempos de trabajo y la incertidumbre por la heterogeneidad en la toma de la muestra que tienen las fermentaciones sólidas.

\section{MATERIALES Y METODOS}

Se describe primero la obtención y pretratamiento de tusas de maíz, luego la preparación del inóculo y del medio de cultivo, se explica el proceso de fermentación sólida, terminando con la captura de imágenes y el análisis fotográfico

\section{Obtención y pretratamiento de tusas de maíz}

La tusa de maíz fue obtenida en la Central Mayorista de Antioquia, ubicada en la ciudad de Itagüí y fue llevada a los laboratorios del Centro de Estudios e Investigación en Biotecnología (CIBIOT) y el Grupo de Investigaciones Agroindustriales (GRAIN), pertenecientes a la Escuela de Ingenieras de la Universidad 
Pontificia Bolivariana. Los requisitos de las tusas para ser llevados al laboratorio fueron tener menos de 8 horas de separación de los granos de maíz para disminuir los riesgos de contaminación y carecer de cualquier tipo de enfermedad visible. Para la desinfección de las tusas, se preparó una solución de hipoclorito de sodio ( $5 \mathrm{ml} /$ I de agua) y se dejaron sumergidas en ella, durante 5 minutos. Una vez pasado el tiempo, fueron lavadas con abundante agua para eliminar los restos del desinfectante. Paso seguido fueron secadas en un horno de convección forzada durante 12 horas a $75^{\circ} \mathrm{C}$. La tusa seca fue almacenada en bolsas resellables por un periodo inferior a 30 días para evitar contaminación con hongos filamentosos.

\section{Preparación del inóculo}

La semilla (spawn) del basidiomiceto Pleurotus pulmonarius se adquirió en el laboratorio de tejidos vegetales de la Universidad de Antioquia. Con la semilla se preparó el inóculo para la FES, el cual se cultivó en agar papa dextrosa (PDA, por sus siglas en inglés) producido por el laboratorio Merck®. La preparación se llevó a cabo según especificaciones técnicas del fabricante (Merk, 2010). Se sembraron aproximadamente $0.5 \mathrm{~g}$ de la semilla de $P$. pulmonarius sobre el agar y se llevó a una cámara de incubación a $27^{\circ} \mathrm{C}$ y en oscuridad, durante 15 días.

\section{Preparación del medio de cultivo y proceso de fermentación sólida}

El medio de cultivo estaba constituido por tusa de maíz, como fuente de carbono y energía, y con el objeto de evaluar el contenido de humedad, $\mathrm{pH}$ y presencia o ausencia de sales se adicionó agua destilada estéril hasta alcanzar los valores requeridos de humedad, cal para ajustar el $\mathrm{pH}$ y la mezcla de sales que estaba compuesta de 0,04 mg/ $100 \mathrm{ml}$ de $\mathrm{MgSO}_{4} ; 0,2 \mathrm{mg} / 100 \mathrm{ml}$ de $\mathrm{K}_{2} \mathrm{HPO}_{4}$, y 0,2 mg/100 ml de $\left(\mathrm{NH}_{4}\right)_{2} \mathrm{SO}_{4}$. Los niveles de las variables fueron para humedad (60\% y $80 \%)$, para $\mathrm{pH}(6$ y 8 ) y para las sales la presencia 0 ausencia de la mezcla que fue descrita anteriormente. Las cajas de Petri fueron inoculadas e incubadas durante 16 y 30 días en una cámara de humedad, protegidas de la luz. Todos los ensayos se realizaron por triplicado. Una vez establecidas las mejores condiciones para cada variable, se hizo una medida de la concentración de proteína a través del método de Biuret.

\section{Captura de imágenes}

Las fotografías fueron tomadas con una cámara Canon Rebel de 15 megapixeles a una altura de $12 \mathrm{~cm}$ y una resolución $4 x$ wide $27 \mathrm{~mm}$ - woxmm, sobre un fondo oscuro. El uso de una cámara semiprofesional o profesional asegura un nivel o cantidad de pixeles adecuado para obtener una fotografía que genere un mapa de bits de alta resolución o altamente detallado, elemento fundamental para las fotografías. Se tomaron en el intervalo de tiempo entre las 11:00 am y la 1:00 pm, con el objetivo de mantener una intensidad luminosa similar, debido a que el medio día en la zona del Ecuador asegura tener la mayor intensidad de la luz del sol en un día despejado.

\section{Análisis fotográfico}

Para el caso de este trabajo, la medida del color, se identificó como el Índice de Blanco (IB), que como se explicó en la introducción, en imágenes policromáticas se puede obtener a partir de calcular en cada pixel el promedio de la intensidad de los colores, en dicha área; mientras estas se localicen más cerca del valor máximo (R: 255, G: 255 y B: 255), tiene mayor intensidad de blanco. En la figura 2 se esquematiza el procesamiento para obtener el IB. El primer paso es capturar una imagen digital del hongo. El segundo paso es seleccionar el área de medida que en este caso es el círculo que delimita la caja de Petri. El tercer paso es obtener una muestra de la información de intensidad de los pixeles ( $\mathrm{Pi}$ ), donde cada pixel se representa como una tripleta de valores entre 0 y 1 con la información de la intensidad de cada color (RGB). El IB de un pixel (IBi), es el promedio de los valores de la tripleta y el índice de blanco del área es el promedio de los índices de blanco de toda la muestra de pixeles (IB). El procedimiento termina reportando el valor final del IB calculado. De acuerdo a lo anterior, una vez tomada la fotografía (en el día 16 o 30), esta era llevada al toolbox de procesamiento digital de imágenes de Matlab, donde era medido el IB, a través de un algoritmo diseñado para medir el blanco en el área de la caja de Petri. Los valores obtenidos de IB fueron analizados estadísticamente en el software Statgraphics XVI centurión.

\section{RESULTADOS Y DISCUSIÓN}

Se utilizó el análisis digital de imágenes para cuantificar, de forma indirecta, el crecimiento del basidiomiceto en la tusa de maíz. El índice de blanco del micelio se utilizó como una referencia indirecta del crecimiento del hongo. En las Figuras de la 3 a 5, se presenta la evaluación preliminar del efecto de la humedad, el pH y la presencia o ausencia de sales sobre el crecimiento de Pleurotus pulmonarius en tusa de maíz. 
De las figuras de la 3 a 5 , se puede evidenciar que hay una diferencia visual apreciable en las réplicas de crecimiento entre $60 \%$ y $80 \%$ de humedad, mostrando una invasión completa del medio en el $80 \%$ de humedad; sin embargo, para el pH y las sales no hay una diferencia apreciable luego de 30 días. Por esta razón, se calculó el IB para cada ensayo, buscando encontrar una diferencia entre un ensayo y otro. En la Tabla 1, se muestran los valores de la medición promedio del IB para cada uno los niveles de los factores estudiados.

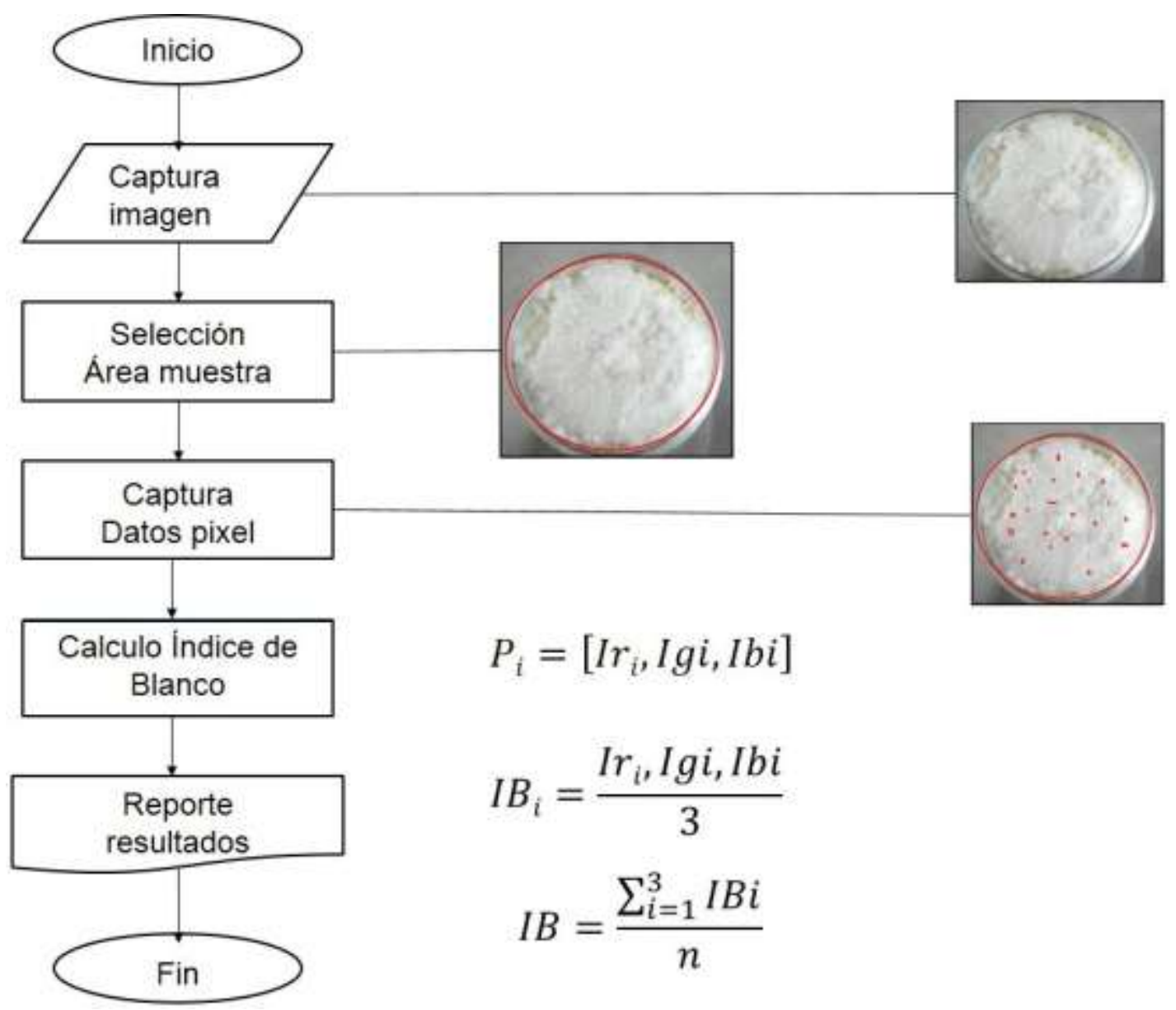

Fig. 2: Esquema del procesamiento digital de imágenes

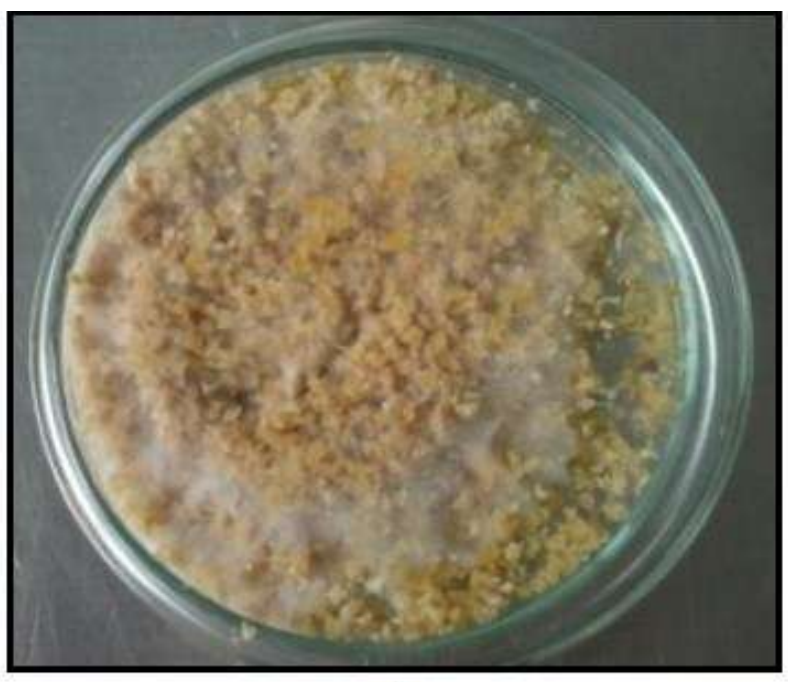

A

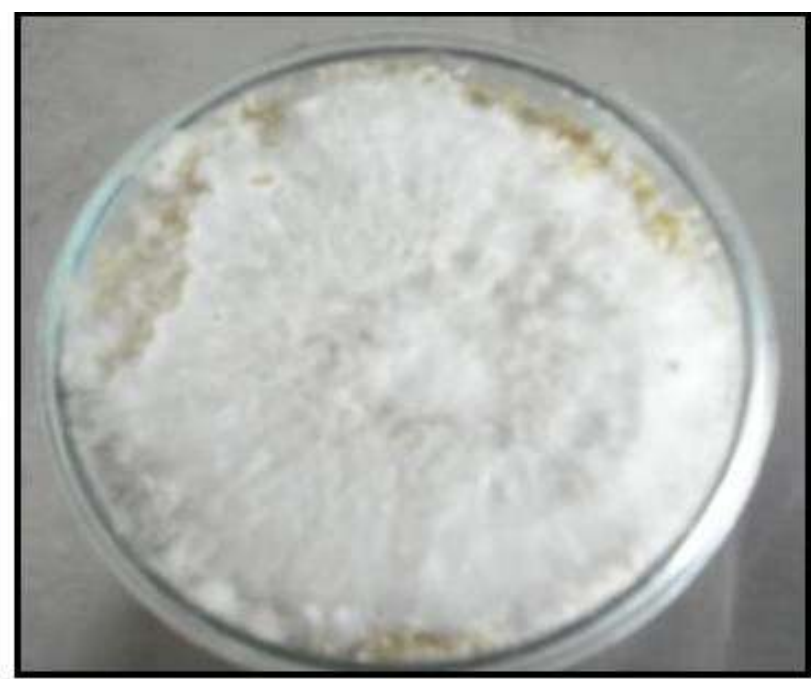

B

Fig. 3: Registro fotográfico de la evaluación del crecimiento de Pleurotus pulmonarius a diferentes contenidos de humedad. (A) $60 \%$, (B) $80 \%$ 


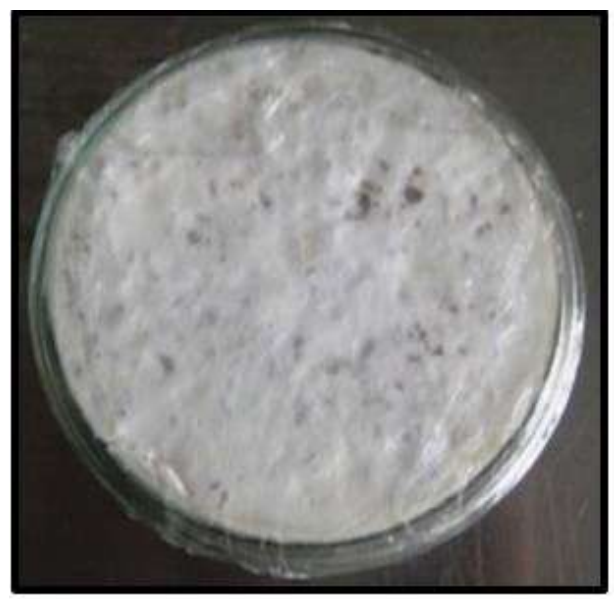

A

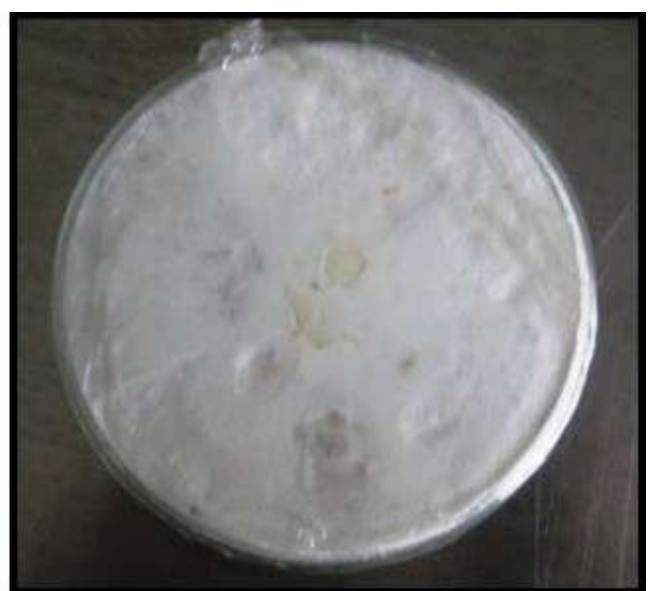

B

Fig. 4: Registro fotografico de la evaluacion del crecimiento del Pleurotus pulmonarius a diferentes condiciones de $\mathrm{pH}$. (A) $\mathrm{pH} 6$, (B) $\mathrm{pH} 8$

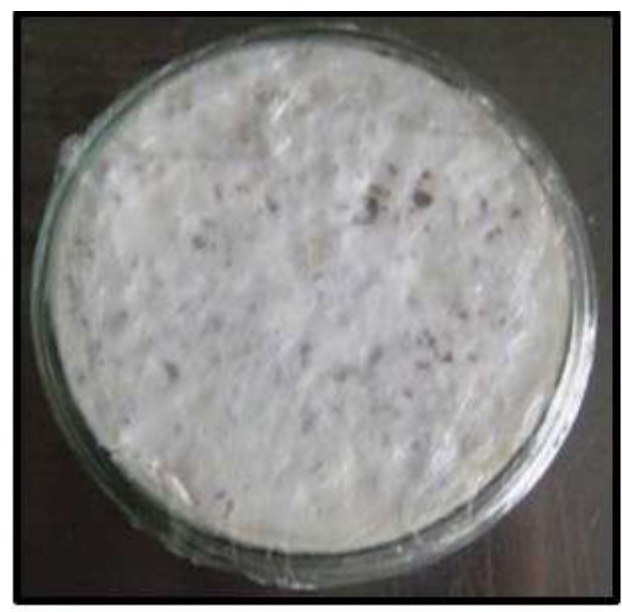

A

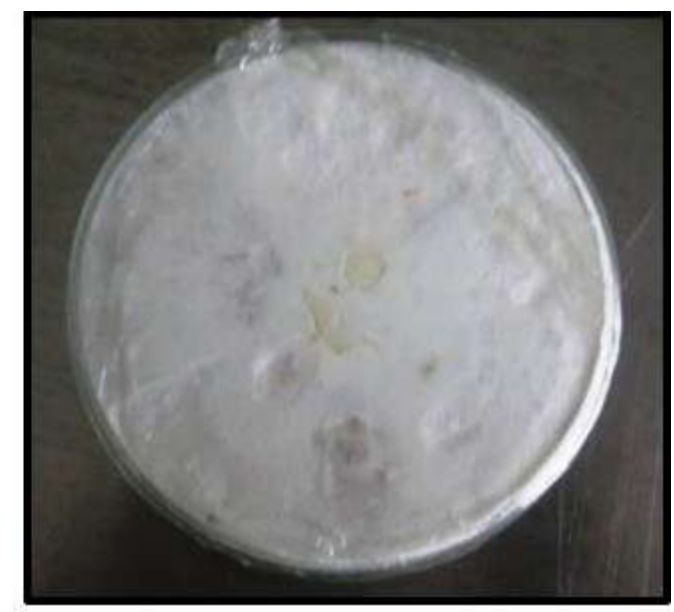

B

Fig. 5: Registro fotografico de la evaluacion del crecimiento del Pleurotus pulmonarius a través de las sales. (A) Con Sales, (B) Sin sales

Tabla 1: Resumen estadístico de los Índices de Blanco para el crecimiento del basidiomiceto

\begin{tabular}{|c|c|c|c|c|c|c|}
\cline { 2 - 7 } \multicolumn{1}{c|}{} & \multicolumn{2}{c|}{ Humedad } & \multicolumn{2}{c|}{$\mathrm{pH}$} & \multicolumn{2}{c|}{ Sales } \\
\hline Análisis & $60 \%$ & $80 \%$ & $\mathrm{pH} 6$ & $\mathrm{pH} 8$ & Presencia & Ausencia \\
\hline IB Promedio & 0,487 & 0,828 & 0,620 & 0,628 & 0,634 & 0,613 \\
\hline Desviación Estándar & 0,022 & 0,015 & 0,015 & 0,016 & 0,007 & 0,003 \\
\hline Coeficiente de Variación & $4,52 \%$ & $1,79 \%$ & $2,47 \%$ & $2,47 \%$ & $1,10 \%$ & $0,49 \%$ \\
\hline Valor t & \multicolumn{2}{c|}{$-25,534$} & \multicolumn{2}{c|}{$-0,779$} & \multicolumn{2}{c|}{5,429} \\
\hline Valor P & \multicolumn{2}{|c|}{$0,00000023775 *$} & \multicolumn{2}{c|}{0,46543} & \multicolumn{2}{c|}{0,00161949 * } \\
\hline
\end{tabular}

Adicional, a la tabla anterior, se determinó que la hipótesis nula indica que las muestras son iguales, mientras que la hipótesis alternativa, indica que son diferentes. De la Tabla 1 se concluye que hay una evidente diferencia en la invasión del micelio del hongo sobre el sustrato para la humedad del $80 \%$. Sin embargo, en el caso del pH y la presencia o ausencia de sales, no hay una diferencia evidente. Puede decirse entonces que los promedios de índice de blanco con mayor diferencia son los del contenido de humedad, mientras que los del $\mathrm{pH}$ y la adición de sales están muy cercanos. Con el ánimo de encontrar diferencia estadísticamente significativa, se realizó un análisis estadístico t de student, suponiendo que se tienen varianzas homogéneas. Según los resultados de la Tabla 1, para el caso de la humedad y el contenido de sales, los valores de $\mathrm{P}$ promedio que aparecen señalados con un asterisco son de $2,3775^{\star} 10$ 7 y 0,00162, respectivamente, indicando que hay diferencia estadísticamente significativa por ser menores de 0,05 . Por lo tanto, se rechaza la hipótesis nula a favor de la alterna, indicando que las muestras son 
diferentes. En el caso del $\mathrm{pH}$, el valor $\mathrm{P}$ promedio es de 0,465 , indicando que no hay diferencia estadísticamente significativa por lo tanto no puede rechazarse la hipótesis nula, es decir las muestras son iguales.

Tomando los resultados anteriores para el contenido de humedad (Figura 3), los valores correspondientes al $80 \%$ de humedad, mostraron un buen crecimiento del hongo en tusa de maíz, debido a que permitieron que el micelio invadiera rápidamente casi todo el sustrato. Esto se debe a que la humedad es un factor que está íntimamente relacionado con el mismo concepto de FES y con las características del sustrato. La importancia del agua en la FES radica en que la mayoría de las células viables tienen un contenido de humedad entre el $70 \%$ y $80 \%$ (Padey et al., 2008). De otro lado, el rápido crecimiento del micelio puede evitar el desarrollo de microorganismos no deseables en el proceso. Encontrar condiciones que favorezcan el rápido crecimiento del micelio puede traer beneficios si se piensa en el escalado del proceso, pues podrían evitar el desarrollo de microorganismos no deseables en el mismo.

Para el pH no se observaron diferencias en la invasión del micelio entre los niveles evaluados, esto debido probablemente a que el rango seleccionado corresponde a los valores de $\mathrm{pH}$ en los que presenta un mayor crecimiento la mayoría de hongos. Así lo afirma Carrillo (2003), quien postula que el crecimiento de los hongos es propicio en rango de $\mathrm{pH}$ de 4 a 8 , presentando los mejores rendimientos entre 5,5 y 6,5, con lo cual podría explicarse que no hubiera una diferencia evidente, aunque como afirman Álvarez y Paredes (2005), el pH se ve influenciado por efectos como la humedad.

En cuanto a la importancia de sales en medio de cultivo para basidiomicetos, autores como Ramos y Ricardo (2007) afirman que estas son útiles para el buen crecimiento de los hongos, especialmente para aumentar el contenido proteico de los sustratos lignocelulósicos; este tipo de residuos, son pobres en proteína y por su composición rica en residuos lingocelulosicos, tienen además el problema de que por su lignina, se convierten en un problema ambiental, por lo que los bioprocesos aparecen como alternativa para tratarlos (Gómez et al., 2013), dándole un valor agregado. Con los resultados obtenidos del crecimiento del Pleurotus pulmonarius en tusa de maíz en las cajas de Petri, los mejores resultados son humedad del $80 \%$, $\mathrm{pH}$ de 6 y con presencia de sales.

Con las condiciones anteriormente establecidas se llevó a cabo una medición, donde se evaluó el crecimiento y vigorosidad del hongo en el sustrato, es decir que el micelio invadiera la mayor cantidad de sustrato. Se midió entonces además del IB, el contenido de proteína como un estimado de la biomasa producida, cuando invadiera completamente el sustrato y cuando presentara una mayor vigorosidad el micelio. En la Figura 6 se muestra el comportamiento del hongo a los 16 (A) y a los 30 días (B). En la figura $6 \mathrm{~A}$, se muestra que a los 16 días el micelio de hongo, invadió completamente la caja de Petri, sin embargo, cuando el cultivo llegó a los 30 días, mostraba más invasión del micelio tal como lo muestra la figura 6B. Para encontrar una diferencia cualitativa, se llevó a cabo la medición del IB, además de la prueba estadística t de student. La Tabla 2, muestra los resultados de dicha medición.

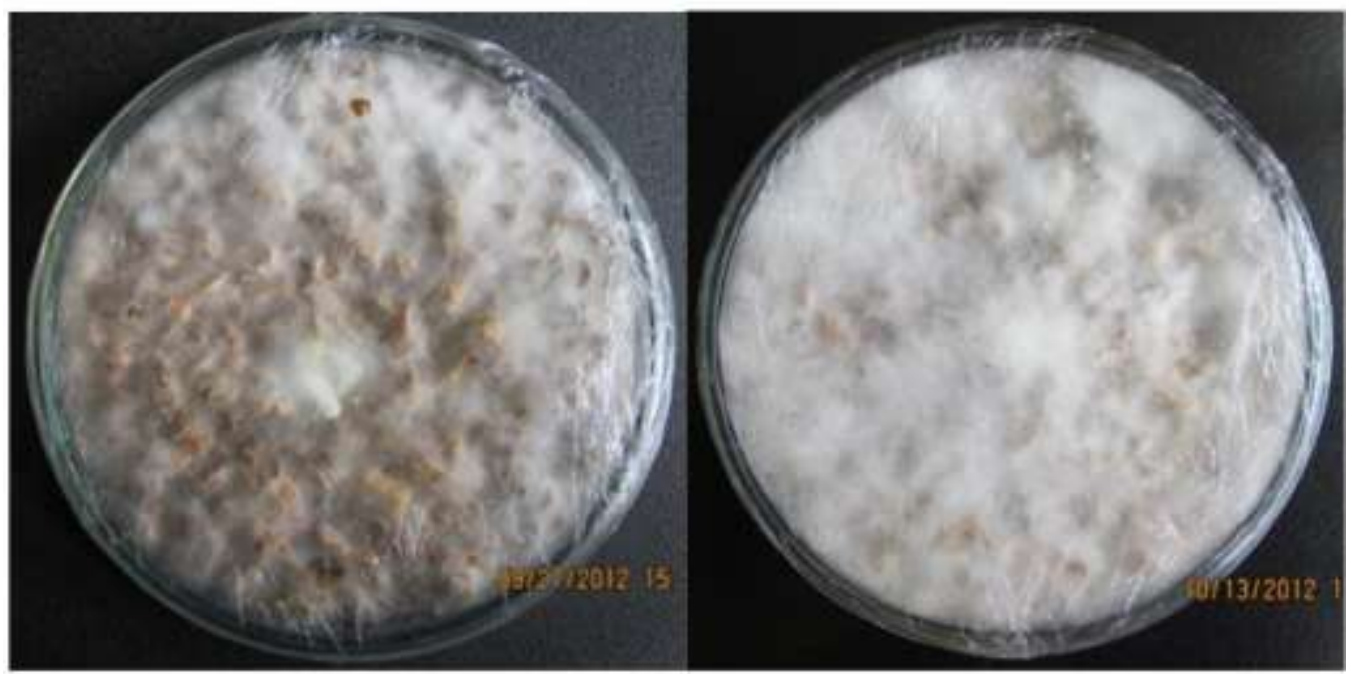

A. 16 dias de crecimiento

B. 30 dias de crecimiento

Fig. 6: Comparación del crecimiento del Pleurotus pulmonarius a los 16 y 30 días. 
Tabla 2: IB para los 16 y 30 días

\begin{tabular}{|c|c|c|}
\hline Análisis & $\begin{array}{c}\text { IB } \\
16 \text { días }\end{array}$ & $\begin{array}{c}\text { IB } \\
30 \text { días }\end{array}$ \\
\hline Promedio & 0,557 & 0,73 \\
\hline Desv. Estándar & 0,019 & 0,017 \\
\hline Coefi.Variación & $3,37 \%$ & $2,38 \%$ \\
\hline Valor $\mathrm{T}$ & \multicolumn{2}{|c|}{$-15,142$} \\
\hline Valor $P$ & \multicolumn{2}{|c|}{$3,58227 \mathrm{E}-07^{*}$} \\
\hline Valor $\mathrm{F}$ & \multicolumn{2}{|c|}{1,17} \\
\hline
\end{tabular}

En la Tabla 2 se muestra una diferencia evidente en las vigorosidades medidas indirectamente a través del IB, entre los basidiomicetos medidos a los 16 y 30 días. Adicionalmente, las concentraciones de proteína para los 16 y 30 días fueron de $0,923 \pm 0,0411 \mathrm{mg}$ de proteína/ $100 \mathrm{ml}$ y de 0,952 $\pm 0,0583 \mathrm{mg}$ de proteína/ $100 \mathrm{ml}$, respectivamente. En la Tabla 2, el valor $\mathrm{F}$ es de 1,17 indicando que no hay diferencia significativa entre las varianzas de los IB a los 16 días y a los 30 días. El valor $t$ de $-15,142$ y el valor $\mathrm{P}$ de $3,58227^{*} 10$ 07, muestran que hay diferencia estadísticamente significativa entre la media del IB a los 16 días y el IB a los 30 días. El empleo de imágenes policromaticas para medir el crecimiento celular ha sido utilizado por Cordoba et al (2010), quienes al igual que en este trabajo, emplearon la escala RGB, con el objeto de medir el crecimiento celular de un clon de Isochrysis galbana a través de la intensidad del color que sus células generan durante las diferentes etapas, sobretodo en la fase exponencial y de estabilización, encontrando un método rápido y económico. Por su parte, Xia et al. (2016), propusieron un método para medir las características de crecimiento y morfología de la colonia del hongo Monascus ruber en FES, de acuerdo a la producción de un pigmento, utilizando la escala RGB. Los autores lograron demostrar que las características morfológicas, especialmente el color producido de la colonia se correlacionó con la producción de pigmentos rojizos. En este trabajo el IB, determinó el que había mejor crecimiento a los 30 días de ensayo. Basados en esto, se decidió esperar 30 días para evaluar el crecimiento del Pleurotus pulmonarius en la tusa de maíz, en futuras investigaciones.

Otros trabajos en donde se midió el crecimiento y características de hongos en medio solido a través de PDI, se pueden reportar los trabajos de Cunha et al. (2012b), los cuales evaluaron el crecimiento de Aspergillus niger en residuos de caña de azúcar y Pujari et al (2011), la presencia de hongos en plantas, que son ricas en lignocelulosa, con la ventaja adicional que permite detectar la presencia de éstos para prevenir enfermedades; inclusive el PDI se ha empleado para medir hongos en la piel humana como lo señalaron Mader et al. (2015). Tal como en este trabajo, se pudo evaluar el crecimiento de una forma rápida y sin el empleo de gran cantidad de reactivos; además, quedan puestas las bases de un método nuevo con el cual se puede medir el crecimiento celular en un sistema complejo y heterogéneo como es la FES.

\section{CONCLUSIONES}

Los resultados arrojados en este trabajo, indican que el Índice de Blanco (IB), puede ser empleado para medir el crecimiento o el vigor del Pleurotus pulmonarius cultivado en tusa de maíz, mostrando como mejores condiciones $80 \%$ de humedad, $\mathrm{pH}$ de 6 y presencia de sales; adicionalmente se presentó diferencia estadísticamente significativa en las variables humedad y $\mathrm{pH}$. Por otra parte, con el IB, se pudo encontrar una diferencia con respecto al tiempo de cultivo del basidiomiceto, señalando que a los 30 días hay un mejor desarrollo o vigor del mismo. De esta forma, el procesamiento digital de imágenes (PDI), aparece como alternativa para la medición del crecimiento del blastomicetos del género Pleurotus spp en FES.

\section{REFERENCIAS}

Alvarez, M. Larrea, P. Paredes, M. Fermentación sólida del banano de rechazo utilizando Aspergillus niger para alimento animal. Recuperado 25 de febrero de 2008 de http://fcial.uta.edu.ec, Ambato: Universidad Técnica (2005)

Arnal-Barbedo, J. G. Digital image processing techniques for detecting, quantifying and classifying plant diseases, doi.org/10.1186/2193-1801-2-660. SpringerPlus, 2, 660 - 671 (2013)

Becker, J. C. Becker, J. Caldwell, G. Zachgo, E Biotechnology. A laboratory course, Second Edition, 119124, Academic Press, New York (1996) 
Carrillo, L. Los Hongos de los Alimentos y Forrajes. Editorial, 1-24, Editorial Salta: Salta (2003)

Cordoba, M; Gutierrez, J. Porta, M. A, doi: 10.1007/s10811-009-9475-0. Evaluation of Isochrysis galbana (clone T-ISO) cell numbers by digital image analysis of color intensity. J Appl Phycol, 22, 427-434. (2010)

Cunha, F. M. y otros seis autores, doi: 10.1007/s12257-011-0405-z, Indirect Method for Quantification of Cellular Biomass in a Solidscontaining Medium Used as Pre-culture for Cellulase Production. Biotechnology and Bioprocess Engineering 17: 100-108 (2012)

Dörge, T., Carstensen, J. M., y Frisvad, J. C. Direct identification of pure Penicillium species using image analysis. Journal of Microbiological Methods, 41(2), 121-33 (2000)

Duan, Y., Wang, L., y Chen, H. doi:10.1016/j.bej.2012.04.020, Digital image analysis and fractal-based kinetic modelling for fungal biomass determination in solid-state fermentation. Biochemical Engineering Journal, 67, 60-67. (2012)

Firrao, G., Torelli, E., Gobbi, E., Raranciuc, S., Bianchi, G., y Locci, R, doi:10.1016/j.jcs.2010.06.017, Prediction of milled maize fumonisin contamination by multispectral image analysis. Journal of Cereal Science, 52(2), 327-330. (2010)

Gómez, E A, Ríos, L.A, y Peña, J.D., Efecto del Pretratamiento de Biomasa Maderera en el Rendimiento a Etanol. Información tecnológica, 24(5), 113-122 (2013)

Gonzalez, R. Wood, R. Digital image fundamentals. Digital Image Processing.(3rd Edition) by Pearson Prentice Hall, 35-103, United States of America (2008)

Guevara, C. A., Arenas, H. A., Mejía, A., y Peláez, C. A. Obtención de Etanol y Biogás a Partir de Banano de Rechazo. Información tecnológica, 23(2), 19-30 (2012)

Hölker, U., y Lenz, J., doi:10.1016/j.mib.2005.04.006, Solid-state fermentation--are there any biotechnological advantages? Current Opinion in Microbiology, 8(3), 301-6. (2005)

Jacobson, R., The manual of photography. 10a ed. Elsevier. Amsterdam. 566p (2010)

Khodaskar, A. y Ladhake, S., Semantic Image Analysis for Intelligent Image Retrieval, ISSN 1877-0509, Procedia Computer Science,. Volume 48, Pages 192-197 (2015)

Mader, $\mathrm{U}$ y otros cinco autores. Image-Processing Scheme to Detect Superficial Fungal Infections of the Skin, http://dx.doi.org/10.1155/2015/851014, Computational and Mathematical Methods in Medicine, Article ID 851014, 9 pages (2015)

Mauro-Diaz, G., Lencinas, J. D., Del Valle, H. Introducción a la fotografía hemisférica en ciencias forestales. Madera y Bosques vol. 20, núm. 1: 109-117 Primavera (2014)

Merck, Potato Dextrose Agar, Microbiology Manual, 1.10130, Darmstadt, Germany 12th Edition, 389 - 390 (2010)

Mitchell, D. Krieger, N. Berovic, M. Solid-State Fermentations Bioreactors. Fundamentals of Design and Operation, 3-4, Springer, Germany (2006)

Ortega, F. A., Pérez, O. A., y López, E. A. Comparación del Desempeño de Estimadores de Estado no Lineales para Determinar la Concentración de Biomasa y Sustrato en un Bioproceso. Información tecnológica, 26(5), 35-44 (2015)

Ortega, F.A, Pérez, Omar A, y López, E.A., Modelo Semifísico de Base Fenomenológica del Proceso Continuo de Fermentación Alcohólica. Información tecnológica, 27(1), 21-32 (2016)

Oviedo, J.C, Casas, A.E., Valencia, J.A., y Zapata, J.E., Análisis de la Medición de la Biomasa en Fermentación en Estado Sólido empleando el Modelo Logístico y Redes Neuronales. Información tecnológica, 25(4), 141-152 (2014)

Padey, A. Soccol, C. Larroche, C. Current Developments in Solid-state Fermentations. 4-8, Asiatech Publishers, INC (Springer),New Delhi: (2008) 
Pujari, J. Yakkundimath, R. Byadgi, A, Image processing based detection of fungal Diseases in Plants, http://www.sciencedirect.com/science/article/pii/S187705091500201X, Procedia Computer Science, International Conference on Information and Communication Technologies (ICICT 2014). 46, 1802 - 1808 (2015)

Raimbault, M, doi: 10.2225/vol1-issue3-fulltext-9, General and microbiological aspects of solid substrate fermentation. Electronic Journal of Biotechnology, 1(2), 174-188. (1998)

Ramos, M.; Ricardo, J. Fermentación en estado sólido (I). Producción de alimento animal. Tecnología Química, XXVII(3), 17-22 (2007)

Rodríguez Couto, S., y Sanromán, M.A., Application of solid-state fermentation to ligninolytic enzyme production. Biochemical Engineering Journal, 22(3), 211-219. (2005)

Shingania, y otros tres autores, doi:10.1016/j.bej.2004.09.013,Recent advances in solid-state fermentation. Biochemical Engineering Journal, 44, 13-18 (2009)

Vega, A. y Franco, H. Productividad y calidad de los cuerpos fructíferos de los hongos comestibles Pleurotus pulmonarius RN2 y P. djamor RN81 y RN82 cultivados sobre sustratos lignocelulósicos. Información tecnológica, 24(1), 69-78 (2013)

Velmurugan, P.,y otros cinco autores. Monascus pigment production by solid-state fermentation with corn cob substrate. Journal of Bioscience and Bioengineering, 112(6), 590-4. doi:10.1016/j.jbiosc.2011.08.009 (2011)

Wayne, R, doi:10.1016/B978-0-12-411484-5.00014-7, Image Processing and Analysis. Light and Video Microscopy (Chapter 14. Second edition). Pages 255-269 (Capitulo de Libro). Academic Press. (2014)

Xia, M., Wang, L., Yang, Z., y Chen, H, doi:10.1007/s10295-015-1729-z, High-throughput screening of high Monascus pigment-producing strain based on digital image processing. Journal of Industrial Microbiology \& Biotechnology. 43 (4), 451-461 (2014) 